\title{
A way forward to discover Antarctica's past
}

\author{
J. S. Wellner \\ University of Houston, Houston, TX 77004, USA \\ Correspondence to: J. S. Wellner (jwellner@uh.edu)
}

Received: 25 September 2014 - Accepted: 24 November 2014 - Published: 22 December 2014

\section{Antarctic Geologic Drilling Workshop - Houston, Texas, 7-8 November 2013}

Fifty-four participants attended the Antarctic Geologic Drilling Workshop (AGDW) to discuss science objectives and develop key projects. The goal of the NSF-sponsored AGDW was specifically to discuss the interests of US-based scientists in Antarctic and Southern Ocean projects, foster interactions within the Antarctic geoscience community, and discuss top-priority scientific questions and technological requirements to advance outstanding scientific goals.

Antarctica, with its thick shroud of glacial ice and fringed belt of floating oceanic ice, offers challenges to unraveling the history of one of Earth's last frontiers. Rocks deposited in and around Antarctica, reachable through a wide-range of innovative geological drilling approaches, formed during times that witnessed climate and ice-sheet changes. Recovery of rocks through drilling expands the understanding of the interplay of Earth's dynamic processes that control and respond to the Antarctic cryosphere.

Much of our knowledge of past climate changes, and inferred ice-sheet history, has been obtained from drill cores taken in low-latitude settings. Such far-field proxies offer an outline of ice-sheet behavior, but cannot show which part of the ice sheet changed or what the ocean currents, temperatures, or other controlling parameters were in ice-proximal settings. Drilling in Antarctica can yield samples of rock that were influenced directly by glacial processes and which provide access to Antarctica's ice-covered geology. Limited outcrops, short gravity cores, and drill cores with partial recovery have been studied from many locations, but such records cannot give the continuous temporal record needed to determine the timing and rates of ice-sheet change or boundary conditions controlling that behavior. Spatially distributed records, including transects from onshore to distal records from each major ice drainage basin, are needed to resolve the individual histories of each area. Seismic data linking drill sites can increase the impact of individual sites by extending the details over a broader area and tightening the time constraints at each site. New over-ice seismic data acquisition through systems like Vibroseis will identify new subglacial drilling targets. New methods to sample bedrock and measure conditions beneath the ice will help refine basal-bed boundary conditions that are vital to reconstructions of icesheet behavior. Numerical modeling can test data-driven hypotheses and evaluate forcing mechanisms under different atmospheric boundary conditions.

Within the workshop discussions, two general themes rose to highest priority. One is on late Quaternary interglacials, when Earth and ocean conditions were similar to today and ice retreated landward of its current position. The other priority is the study of mid-Cenozoic ice-sheet history during times when boundary conditions of high atmospheric $\mathrm{CO}_{2}$ approached those estimated for the next century, but when Earth and ocean conditions were different from today. Combining records of ice-sheet behavior during these two time intervals and these two sets of conditions that are converging in our future will yield information needed to advance the development of computer simulations for studies of near-term future behavior of Antarctica's ice sheets.

The full report is available at http://agdw.uh.edu/. 